\title{
Improvement of Transient Stability using TCSC
}

\author{
Surender Reddy Salkuti \\ Department of Railroad Electrical Systems Engineering, \\ Woosong University, Jayang-Dong, Dong-Gu, Daejeon, Republic of Korea. \\ surender@wsu.ac.kr
}

\begin{abstract}
Stability is a major issue which explains stable operation of electrical power system. Conventional methods adopted for the enhancement of transient stability (TS) include circuit breakers, fast acting exciters, and reduced total transfer reactance of the system. In this paper, Flexible AC Transmission System (FACTS) controller is used for effective utilization of transmission system. This controller improves the performance of transient stability (TS) and power flow. Simulations are performed to enhance the TS of Western System Coordinating Council (WSCC) 9 bus and 5 bus test systems with fixed compensation on different lines, and the optimal placement has been examined for improved results. For further improving the transient stability margin (TSM), a Thyristor Controlled Series Controller (TCSC) has been employed, and the simulation results show the suitability and effectiveness of TCSC for enhancing TS of power system.
\end{abstract}

Keywords: Transient Stability, Stability Margin, FACTS controllers, Thyristor Controlled Series Compensator.

\section{Introduction}

Power system stability is a major issue for the secure operation of power system. Many important blackouts caused by the instability of power system have explained the importance of this concept. As many power networks have emerged through increasing growth in interconnections, the use of new controls and technologies, and increased operation in the highly stressed operating conditions, various forms of system instability have evolved. Detailed analysis of various methods of instability, and how they are correlated is important for satisfactory operation and design of power systems [1-2].

Generally, the power system is a highly non-linear that operates in an eternally modifying environment with generator power outputs, load demands and key operating parameters are updated/modified regularly. However, when subjected to a disturbance, the stability of system depends on initial operating conditions and nature of disturbance [3]. The categorization of power system stability introduced in this paper and it is based on following discussions [4-5]:

- Physical behavior of resulting disturbance of a system can be considered as main system in which the instability can be noticed.

- Size of selected instability influences the type of prediction and computation of stability.

- Processes, devices, time span should be taken into selection to obtain the stable operating condition.

During steady state operation, TCSC helps in increasing and controlling power flow through a transmission line. Another important feature of TCSC is that, it's use during the major disturbances such as faults, due to their capability to enhance TS of the system. Effects of TCSC on variation of TS condition of power system by incorporating both generators and network, have been proposed and simulated in references [6-7]. Reference [8] addresses the variable effective constitutive equivalent reactance capability of TCSC for improving the TS of power systems. For accessing varying effective constitutive equivalent reactance, two various controllers, i.e., a speed deviation based self-tuning Fuzzy type Proportional Integral Derivative (PID) controller and a non-linear controller are utilized. Various control features related to use

Received: January $17^{\text {th }}, 2016$. Accepted: September $25^{\text {th }}, 2018$

DOI: $10.15676 /$ ijeei.2018.10.3.8 
of TCSC for the stability development of power systems are presented in [9]. Reference [10] presents a comprehensive review of general methods of FACTS devices. Reference [11] presents the effects of TCSC for improving the TS of single machine connected to infinite bus system with the selection of resistance of transmission line. To enhance the TS margin, a series FACTS controller is assigned, and the advantage of utilization of TCSC with fuzzy controller over fixed capacitor operation is presented in [12].

A fuzzy logic controller for a TCSC to enhance power system transient stability is presented in [13]. Reference [14] proposes an eigen value based method for the analysis and improvement of steady state and TS of system using TCSC. An approach is proposed in [15] for modeling and parameters setting of TCSC in multi-machine power system to improve TS of the system. A new non-linear control scheme for TCSCs has been proposed in [16] to analyze TS of a multi-machine power system. Fuzzy based damping controller for TCSC to enhance the TS of power systems is proposed in [17]. Reference [18] presents an approach for optimal tuning the parameters of TCSC for the TS of power system.

To enhance the transient stability margin (TSM), a series FACTS controller has been introduced in this paper. A fuzzy controlled TCSC has been utilized, and results show the effectiveness of proposed approach in enhancing the TS of power system. The trajectory sensitivity analysis (TSA) has been utilized to measure the TS condition of power system. TCSC is designed by a variable capacitor, the value of which modifies with the firing angle. It has been shown that the TSA can be utilized in designing the controller. Optimal placement of TCSC controller for various fault conditions can also be recognized with the help of TSA. Simulation studies have been carried out to enhance TS of WSCC 3 machine 9 bus and 5 bus test systems. This paper presents the advantage of the utilization of proposed approach by using the TCSC.

The rest of present paper is organized as follows: Section 2 presents the analysis of transient stability (TS) and modeling of power system. Section 3 presents the TS of the multi-machine power system using network reduction technique and TCSC. Modeling of TCSC and power system is described in Section 4. The trajectory sensitivity analysis (TSA) is described in Section 5. Section 6 describes the results and discussion. Contributions with concluding remarks are presented in Section 7.

\section{Transient Stability (TS) Analysis}

For small disturbances, swing equation can be linearized leading to the concept of steady state stability. There is no available generalized criteria for explaining the system stability with large disturbances (i.e., TS) [19]. Operating characteristics of induction and synchronous machines are presented by a set of differential equations. The solution of network equations retains the identity of system, and hence contributes to the system currents and voltages during the transient period [20]. The modeling of system is presented next:

\section{A. Generator Modeling}

Synchronous machine is depicted by a voltage source, in back of a transient reactance, which is sustained in magnitude, but modifications in the angular position. If rotational power losses of machine due to such effects as friction and windage are negligible, then the difference between electrical and mechanical power equal to the accelerating power [6]. Classical model of generator is depicted in Figure 1.

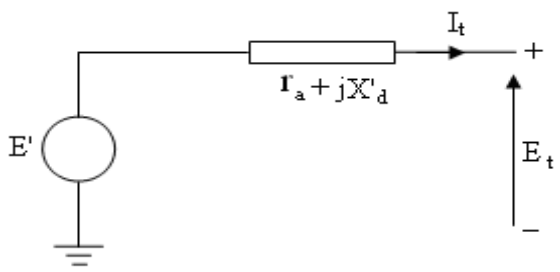

Figure 1. Classical Model of Generator. 
The classical model can be explained by following a set of algebraic and differential equations: Algebraic Equations:

$$
E^{\prime}=E_{t}+r_{a} I_{t}+j x_{d}^{\prime} I_{t}
$$

Differential Equations:

$$
\begin{aligned}
& \frac{d \delta}{d t}=\omega-2 \pi f \\
& \frac{d^{2} \delta}{d t^{2}}=\frac{d \omega}{d t}=\frac{\pi f}{H}\left(P_{m}-P_{e}\right)
\end{aligned}
$$

\section{B. Demands/loads Representation}

Except motors power system demands/loads are depicted by equivalent circuits, during the transient period it can be treated as many ways. Generally utilized demand/load representations are either static admittance or impedance to ground; active and reactive powers are constant. The parameters related with constant current and static impedance representation of demands/loads are accessed from scheduled bus loads. The bus voltages are computed from a power flow solution for power system prior to the disturbance [5]. Initial values of current for a sustained current representation of demands/loads are accessed from the following equation:

$$
I_{p o}=\frac{P_{l p}-j Q_{l p}}{E_{p}^{*}}
$$

The static admittance $\left(\mathrm{Y}_{\mathrm{po}}\right)$ is utilized to depict the load demand at bus $\mathrm{P}$, and can be accessed using,

$$
Y_{p o}=\frac{I_{p o}}{E_{p}}
$$

The diagonal elements of $\mathrm{Y}_{\text {Bus }}$ (i.e., admittance matrix) corresponding to load/demand bus are changed by using $\mathrm{Y}_{\text {po }}$.

\section{Simulation of Faults}

A fault near or at a bus is represented by suitably modifying the self-admittance of bus. In 3 phase fault, the faulted bus has same potential as ground, the fault impedance is zero. This includes locating infinite shunt admittance, and the bus voltage effect is zero. Fault is removed by replacing the shunt admittance to suitable value depending on the post-fault configuration of the system [21].

\section{Simulation of Fault in the Power System Studies}

Here, the symmetrical fault is simulated in one of the transmission lines at a time. The simulation studies are performed in the following 3 steps [22]:

Step 1: Pre-fault system is executed for a small time (assume $1 \mathrm{sec}$ ) until the system is initialized. Step 2: Then, the fault is applied at one end of the line. Simulation of this faulted condition sustains until the line is disconnected from the buses at both the ends of faulted line after a time tcl (fault clearing time). The time gap between the tripping of breakers at two ends is neglected and analyzed the clearing time. Therefore, the disconnection of line at two ends can be selected simultaneously.

Step 3: Third step is post-fault system simulation. In this system, totally faulted line is disconnected from the system. Simulation is performed for a longer time (assumes 10-20secs) to notice the nature of transients.

In the present paper, TS analysis is done for the single machine and multi machine power systems.

\section{E. Single Machine Connected to an Infinite Bus}

Under large disturbances, the transient stability applied for the stability analysis. Therefore, the non-linear ties to the design should be selected in the analysis. For the swing equation the analytical solutions are not available, numerical methods should be utilized [23]. 


\section{F. Numerical Solution by using Point-by-Point Method}

Point-by-Point method or step-by-step method permits the numerical solution of swing equation. In this process, single or multiple variables are considered to remain constant or to vary according to the considered laws throughout a short interval of time $(\Delta t)$. The Swing equation, neglecting damping term can be expressed using the equations (2) and (3) [24]. If over an interval (say $\mathrm{K}^{\text {th }}$, defined from the instant $\mathrm{t}_{(\mathrm{k}-3 / 2)}$ to $\left.\mathrm{t}_{(\mathrm{k}-1 / 2)}\right)$, the accelerating power $\left(\mathrm{P}_{\mathrm{a}}\right)$ is considered to be constant (at the value computed at $\mathrm{t}_{(\mathrm{k}-1)}$ ), then

$$
W_{(K-1 / 2)}=W_{(k-1 / 2)}+(\Delta t / M) P_{a(k-1)}
$$

If the speed calculated at $\mathrm{t}_{(\mathrm{k}-1 / 2)}$ is assumed to be constant throughout the interval from $\mathrm{t}_{(\mathrm{k}-1)}$ to $\mathrm{t}_{\mathrm{k}}$, then

$$
\delta_{k}=\delta_{(k-1)}+W_{(k-1 / 2)} \Delta t
$$

Defining,

$$
\Delta \delta_{k}=\delta_{k}-\delta_{(k-1)}
$$

We can express,

$$
\Delta \delta_{k}=\Delta \delta_{k-1}+\frac{\Delta t^{2}}{M} P_{a(k-1)}
$$

The above equation enables the computation of angle directly without recourse to the computation of the speed.

\section{G. Equal Area Criteria}

To test the stability of single machine connected to infinite bus power system, there is an easy and straight forward approach which doesn't need the solution of swing equation following the disturbances. The fundamental for this approach is that, in the first equation the system is stable, after the disturbances the rotor angle reaches to a maximum value that time we consider rotor angle initially accelerated and then oscillates about final steady state value. Hence, the stability is ascertained by observing the deviation of rotor angle speed ( $\mathrm{d} \delta / \mathrm{dt})$, and confirming the rotor angle becomes zero following the disturbances. The swing equation is expressed by [25],

$$
M \frac{d^{2} \delta}{d t^{2}}=P_{a}=P_{m}-P_{e}
$$

Multiplying both the sides of Eq. (9) with $\mathrm{d} \delta / \mathrm{dt}$, and then integrating with respect to time,

$$
\begin{aligned}
& M \int_{t_{0}}^{t} \frac{d \delta}{d t} \frac{d^{2} \delta}{d t^{2}} d t=P_{a}=\int_{t_{0}}^{t}\left(P_{m}-P_{e}\right) \frac{d \delta}{d t} d t \\
& \frac{1}{2} M\left(\frac{d \delta}{d t}\right)^{2}=\int_{\delta_{0}}^{\delta}\left(P_{m}-P_{e}\right) d \delta
\end{aligned}
$$

Here, it is considered that at $\mathrm{t}=\mathrm{t}_{0}$, system is at rest i.e., in equilibrium state the speed deviation is zero. In the above expression right hand side equation can be analyzed as the area between curves $\mathrm{P}_{\mathrm{e}}$ vs $\delta$ and $\mathrm{P}_{\mathrm{m}}$ Vs $\delta$. Here, $\mathrm{P}_{\mathrm{m}}$ vs $\delta$ is a horizontal line, and $\mathrm{P}_{\mathrm{m}}$ is considered as a constant. $\mathrm{P}_{\mathrm{e}}$ vs $\delta$ is power angle curve, and it gives the stability of the system using equal area criteria [26]. For the system is to be stable,

$$
\left.\frac{d \delta}{d t}\right|_{\delta=\delta_{\max }}=0
$$

This shows that the area is indicated by,

$$
A=\int_{\delta_{0}}^{\delta_{\max }}\left(P_{m}-P_{e}\right) d \delta
$$

We should have $A_{1}$ is positive portion for which $\mathrm{P}_{\mathrm{m}}>\mathrm{P}_{\mathrm{e}}$, and $\mathrm{A}_{2}$ is negative portion for which $\mathrm{P}_{\mathrm{m}}<\mathrm{P}_{\mathrm{e}}$. Here $\mathrm{A}_{1}$ and $\mathrm{A}_{2}$ magnitudes should be same, i.e., the difference between the positive portion and negative portion is equal to zero.

$$
A=A_{1}-A_{2}=0
$$

Here, the fault is assumed to be a transient one, which is cleared by the time of first reclosure. In case of a permanent fault, this system completely falls apart. In the multi machine system the above case will not be applied. In equal area criteria, the condition for the system to be stable is stated that, if area under $\mathrm{P}_{\mathrm{a}}-\delta$ curve decreases to zero at some value of $\delta$ [27]. 


\section{Transient Stability of Multi-Machine Power System}

Procedure for determining the stability of multi-machine system is described below:

Step 1: From the pre-fault power flow information, find $E_{k}^{\prime}$ for every generating unit. This will give $\left|E_{k}\right|$, which will remain constant during the study and $\delta_{k}^{0}=$ angle of $\left(E_{k}\right)$. Here, it is also observed that the prime mover inputs to generating units, $P_{m k}=P_{g k}^{0}$.

Step 2: Augment the power flow network with generator transient reactances. And shift the network buses behind the transient reactances.

Step 3: $Y_{\text {bus }}$ (admittance matrix) is calculated for different network conditions: during the fault and post fault i.e., faulted line is cleared, after the line reclosure.

Step 4: In the faulted mode, from power angle equations generator outputs may be calculated. Solve the swing equations using Step-by-Step approach or Point-by-Point approach or any integration techniques like changed Runga Kutta fourth order method, Euler's method, etc.

Step 5: Repeat the above step for after line reclosure mode and post fault mode.

Step 6: Study the $\delta(\mathrm{t})$ graphs for all generating units, and accomplish the answer to the stability question.

The algorithm for network reduction technique is presented next:

A. Algorithm for Network Reduction Technique

Data Preparation Module:

To perform the TS study, the following data is required [28]:

i. Calculate the mechanical power $\left(\mathrm{P}_{\mathrm{m}}\right)$ of generating units using the power flow study of pre transient network, and also find values of $\mathrm{E}_{\mathrm{i}}\left\llcorner\delta_{\mathrm{i} 0}\right.$ for all generating units. From the load bus data the equivalent impedance of the loads are accessed.

ii. System data:

a. The direct axis transient reactance $\left(\mathrm{X}_{\mathrm{d}}{ }^{\prime}\right)$ and inertia constant $(\mathrm{H})$ for all generating units.

b. For the initial network conditions transmission network impedances are used and the subsequent switching like breaker reclosings and fault clearing.

iii. Maximum time for which a solution to be considered, time of switching, placement and type of disturbance.

\section{Preliminary computations:}

To prepare the data required to perform the TS study, following preliminary computations are needed:

1. All the system data are changed to one common base.

2. The load demands are changed to equivalent admittances or equivalent impedances. The data required for this step is accessed from power flow study. Therefore, if a certain load bus has a voltage $\left(\mathrm{V}_{\mathrm{L}}\right)$, power $\left(\mathrm{P}_{\mathrm{L}}\right)$, reactive power $\left(\mathrm{Q}_{\mathrm{L}}\right)$, and current $\left(\mathrm{I}_{\mathrm{L}}\right)$ flowing through the load admittance $\mathrm{Y}_{\mathrm{L}}=\mathrm{G}_{\mathrm{L}}+\mathrm{j} \mathrm{B}_{\mathrm{L}}$, then

$P_{L}+j Q_{L}=V_{L} I_{L}^{*}=V_{L}\left[V_{L}\left(G_{L}-j B_{L}\right)\right]=V_{L}^{2}\left(G_{L}-j B_{L}\right)$

Equivalent shunt admittance of the bus is represented by,

$Y_{L}=\left(\frac{P_{L}}{V_{L}^{2}}\right)-j\left(\frac{Q_{L}}{V_{L}^{2}}\right)$

3. From power flow data the internal voltages of generating units $E_{i}\left\llcorner\delta_{\text {io }}\right.$ are computed. By using the pre-transient terminal voltages $V\llcorner\alpha$, the internal angles can be calculated. Suppose, the terminal voltage is temporarily selected as a reference, then $\mathrm{I}=\mathrm{I}_{1}+\mathrm{j} \mathrm{I}_{2}$, and by using the relation $\mathrm{P}+\mathrm{jQ}=\mathrm{VI} *$. Find $\mathrm{E} L \delta^{\prime}$ using,

$\mathrm{E} L \delta^{\prime}=\left(\mathrm{V}+\mathrm{QX}_{\mathrm{d}}{ }^{\prime} / \mathrm{V}\right)+\mathrm{j}\left(\mathrm{PX}_{\mathrm{d}}{ }^{\prime} / \mathrm{V}\right)$

By applying the pre-transient voltage angle $\alpha$ to $\delta$ ', or $\delta_{0}=\delta^{\prime}+\alpha$, initial generator angle $\delta_{0}$ is accessed.

4. The $\mathrm{Y}_{\text {bus }}$ matrix is computed for every network condition. 
5. Finally, except the internal generator nodes we discard all the nodes, and $\mathrm{Y}_{\text {bus }}$ matrix is accessed for this reduced network. Reduction can be obtained by using the matrix operation. Except for the internal generator nodes all nodes have zero injection currents. This technique is used to access the network reduction, and is explained as follows,

$$
I=Y V=\left[\begin{array}{c}
I_{n} \\
0
\end{array}\right]
$$

$\mathrm{V}$ and $\mathrm{Y}$ matrices are partitioned accordingly, and we get

$$
\left[\begin{array}{c}
I_{n} \\
0
\end{array}\right]=\left[\begin{array}{ll}
Y_{n n} & Y_{n r} \\
Y_{r n} & Y_{r r}
\end{array}\right]\left[\begin{array}{l}
V_{n} \\
V_{r}
\end{array}\right]
$$

where $n$ denotes the generator nodes and $r$ denotes the remaining nodes. The size of $V_{n}$ is $\left(\mathrm{n}^{*} 1\right)$ and the size of $\mathrm{V}_{\mathrm{r}}$ is $\left(\mathrm{r}^{*} 1\right)$. Expanding the above matrix,

$$
\begin{aligned}
\mathrm{I}_{\mathrm{n}} & =\mathrm{Y}_{\mathrm{nn}} \mathrm{V}_{\mathrm{n}}+\mathrm{Y}_{\mathrm{nr}} \mathrm{V}_{\mathrm{r}} \\
0 & =\mathrm{Y}_{\mathrm{rn}} \mathrm{V}_{\mathrm{n}}+\mathrm{Y}_{\mathrm{rr}} \mathrm{Vr}
\end{aligned}
$$

Eliminate $\mathrm{V}$, to find

$$
\mathrm{I}_{\mathrm{n}}=\left(\mathrm{Y}_{\mathrm{nn}}-\mathrm{Y}_{\mathrm{nr}} \mathrm{Y}_{\mathrm{rr}}^{-1} \mathrm{Y}_{\mathrm{rn}}\right) \mathrm{V}_{\mathrm{n}}
$$

The matrix $\left(Y_{n n}-Y_{n r} Y_{r r}^{-1} Y_{r n}\right)$ is the desired reduced admittance matrix $Y$ of size $(n * n)$. The network reduction technique is a convenient method which can be used only when the load demands are considered as constant impedances. Network reduction technique is applied to the nodes whose current injection is zero.

\section{B. Variable Series Compensation}

It is recognized that series reactive impedance of transmission line primarily limited by the ac power transmission over long lines. With the FACTS technology, it is explained that the variable series compensation is very effective in controlling load flow in line and in improving the stability. Series capacitors are employed in order to increase the loadability and stability of HV transmission systems. The objective is to satisfy inductive voltage drop in the line by an inserted capacitive voltage or to reduce effective reactance of line. The inserted voltage contributed by a series capacitor is in proportion to and in quadrature with line current. Thus, the generated reactive power contributed by capacitor has a self-regulating impact. The objectives of series compensation are voltage stability, development of power oscillation damping, transient stability and sub-synchronous oscillation damping [24].

\section{TCSC}

Figure 2 depicts the schematic diagram of TCSC includes series compensating capacitor in parallel with a thyristor controlled reactor (TCR). In practice, the TCSC implementation, many fundamental compensators may be connected in series to access operating characteristics and desired voltage rating [22].

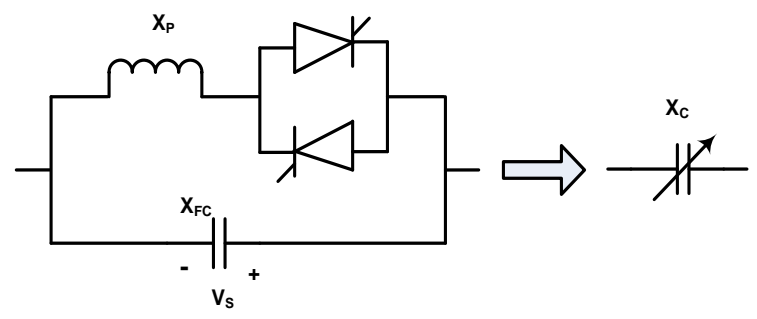

Figure 2. Schematic Diagram of TCSC.

The structure of TCSC is similar to the Thyristor Switched Series Capacitor (TSSC), and if $\mathrm{X}_{\mathrm{L}}$ is smaller than that of $\mathrm{X}_{\mathrm{C}}$, then it can be operated in ON/OFF manner like TSSC. TCR at basic system frequency is a continuously variable reactive impedance, controllable by firing angle $\alpha$, the steady state impedance of TCSC is expressed as [26],

$\mathrm{X}_{\mathrm{TCSC}}(\alpha)=\left(\mathrm{Xc}^{*} \mathrm{X}_{\mathrm{L}}\right) /\left(\mathrm{X}_{\mathrm{L}}(\alpha)-\mathrm{Xc}\right)$

where $X_{L}(\alpha)=X_{L} * \pi /(\pi-2 \alpha-\sin \alpha), X_{L} \leq X_{L}(\alpha) \leq \infty, X_{L}=\omega L$. 


\section{Modeling of TCSC and Power System}

Figure 2 depicts the model of TCSC. Total reactance $\left(\mathrm{X}_{\mathrm{C}}\right)$ of TCSC [6] is described in terms of $\alpha$ (i.e., firing angle) as,

where

$$
X_{C}=\beta_{1}\left(X_{F C}+\beta_{2}\right)-\beta_{4} \beta_{5}-X_{F C}
$$

$$
\begin{aligned}
& \beta_{1}=\frac{2(\pi-\alpha)+\sin 2(\pi-\alpha)}{\pi}, \beta_{2}=\frac{X_{F C} X_{P}}{X_{F C}-X_{P}}, \beta_{3}=\sqrt{\frac{X_{F C}}{X_{P}}}, \quad \beta_{4}=\beta_{3} \tan \left[\beta_{3}(\pi-\alpha)\right]-\tan (\pi-\alpha) \\
& \beta_{5}=\frac{4 \beta_{2}^{2} \cos ^{2}(\pi-\alpha)}{\pi X_{P}}
\end{aligned}
$$

In this paper, it is considered that TCSC is operated in the capacitive mode.

\section{A. The proposed control scheme}

In next level, a controller is used with TCSC. The control scheme that is used in this paper is depicted in Figure 3 [19].

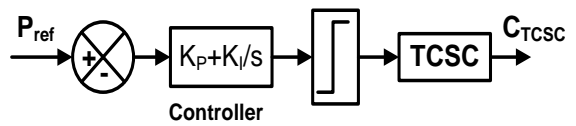

Figure 3. Block Diagram of Proposed Control Scheme.

The active power flow through a line consisting TCSC is considered as the control variable. It is compared with $\mathrm{P}_{\text {ref }}$, and error is fed to the Proportional Integral (PI) controller. The output of proportional integral is the firing angle of $\operatorname{TCSC}(\alpha)$. This $\alpha$ is passed through a limiter to keep it within the capacitive operating zone of TCSC (i.e., $145^{\circ}$ to $180^{\circ}$ ). The output of limiter is supplied to the TCSC firing circuit. $\mathrm{C}_{\mathrm{TCSC}}$ is involved in line dynamics. The proper choices of suitable values of controller constants (i.e., $\mathrm{K}_{\mathrm{I}}$ and $\mathrm{K}_{\mathrm{P}}$ ) are important [27].

\section{Trajectory Sensitivity Analysis}

A. Calculations of Trajectory Sensitivity

The multi-machine power system is depicted by,

$$
\dot{x}=f(t, x, \lambda), \quad x\left(t_{0}\right)=x_{0}
$$

The sensitivities of state trajectories w.r.t. system parameters can be determined by perturbing $\lambda$ from its nominal value $\lambda_{0}$. The trajectory sensitivity [6] expressions are,

$$
\dot{x_{\lambda}}=\left[\frac{d f}{d x}\right] x_{\lambda}+\left[\frac{d f}{d \lambda}\right], \quad x_{\lambda}\left(t_{0}\right)=0
$$

Where $x_{\lambda}=\partial x / \partial \lambda$. By using the numerical method the sensitivities can be determined easily, and is presented next:

\section{B. The Numerical Evaluation: Alternative to Reduce Calculation}

In this approach, we consider one scalar parameter $(\lambda)$, and sensitivities are obtained with it. Two values of $\lambda$ are considered (say $\lambda_{1}$ and $\lambda_{2}$ ). The corresponding state vectors $x_{1}$ and $x_{2}$ are calculated. The sensitivity at $\lambda_{1}$ is represented as [25],

$$
\text { Sens }=\frac{x_{2}-x_{1}}{\lambda_{2}-\lambda_{1}}=\frac{\Delta x}{\Delta \lambda}
$$

If $\Delta \lambda$ is small, then sensitivity is expected to close to the analytically computed trajectory sensitivity. The sensitivity of $\delta_{i j}$ with respect to $\lambda$ is calculated by,

$$
\frac{\partial \delta_{i j}}{\partial \lambda}=\frac{\partial \delta_{i}}{\partial \lambda}-\frac{\partial \delta_{j}}{\partial \lambda}
$$

Here, we have considered the sensitivity of relative rotor angle, instead of sensitivity of $\delta$ of an individual machine. 


\section{Quantification of Trajectory Sensitivity}

Trajectory sensitivities $\left(\partial \delta_{i j} / \partial \lambda\right)$ and $\left(\partial \Delta \omega_{r i} / \partial \lambda\right)$ gives the knowledge about the effect of change of parameter on individual state variables, and therefore on the generators of system. Despite, to know total system condition, we require summing up all these information. The norm of sensitivities of $\delta_{i j}$ and $\Delta \omega_{r i}$ are computed. Sensitivity norm for m machine power system is expressed by [23],

$$
S_{N}=\sqrt{\sum_{i=1}^{m}\left[\left(\frac{\partial \delta_{i j}}{\partial \lambda}\right)^{2}+\left(\frac{\partial \Delta \omega_{r i}}{\partial \lambda}\right)^{2}\right]}
$$

where $\eta$ is termed as inverse of maximum of $\mathrm{S}_{\mathrm{N}}$, i.e., $\eta=1 / \max \left(S_{N}\right)$. As the system moves towards the instability, the oscillation in the trajectory sensitivity will result in higher values of $S_{N}$. This will result in the smaller values of $\eta$. Generally, $\eta$ must be zero at the point of instability. Hence, $\eta$ indicates the distance from the instability. In this work, $\eta$ is utilized for assessing relative stability conditions of the system with various values of tcl, firing angle of TCSC and system load demand [23]. Here, we have assumed a fault in one of the lines of system. The postfault conditions are analyzed by sustainly increasing the tcl [21].

\section{Results and Discussion}

In this section, the case studies are performed on Western System Coordinating Council (WSCC) 9 bus and 5 bus test systems. Let $\eta_{0}$ represents the value of $\eta$ for the case without any TCSC, i.e., base case. Here, the TCSC is located in an open loop in one of the lines at a time, and then the corresponding $\eta$ values are evaluated for different fault locations. The obtained values are normalized with respect to $\eta_{0}$. Hence, if the value of normalized $\eta$ in a certain operating condition is more than 1 , then it represents that absolute value of $\eta$ is more than $\eta_{0}$. Table 1 presents the values of normalized $\eta$ for different combinations of fault locations and TCSC when the faults cleared by line isolation. Here, it is considered that the faults are located near to one of the load buses (i.e., bus 5, 6 or 8 ) in all the case studies. The value of fault clearing time (tcl) is considered as $0.15 \mathrm{sec}$ and firing angle $(\alpha)$ of TCSC as $160^{\circ}$. Here, $\eta$ gives the TSM of system. For TS improvement, higher values of $\eta$ represents the preferable locations of TCSC.

\section{A. Simulation Results on 9 Bus System}

Here, a 3 phase fault is simulated in one of the lines of 9 bus system. The simulation is performed in 3 steps. Initially, pre-fault system is run for a small time. After that, a symmetrical fault is applied at one end of the line. Simulation of faulted condition sustains till the fault is cleared after a time tcl. Then, the post-fault system is simulated for a more time (assume $5 \mathrm{sec}$ ) to notice the nature of transients. Fault can be the self-clearing type or can be cleared by isolating the faulted line.

Table 1. Normalized $\eta$ (ETA) values of 9 bus system for TCSC placed in different fault locations.

\begin{tabular}{|c|c|c|c|c|c|c|c|}
\hline $\begin{array}{c}\text { Fault } \\
\text { at bus }\end{array}$ & $\begin{array}{c}\text { Line } \\
\text { Isolated }\end{array}$ & $\begin{array}{c}\text { Line } \\
4-5\end{array}$ & $\begin{array}{c}\text { Line } \\
5-7\end{array}$ & $\begin{array}{c}\text { Line } \\
4-6\end{array}$ & $\begin{array}{c}\text { Line } \\
6-9\end{array}$ & $\begin{array}{c}\text { Line } \\
7-8\end{array}$ & $\begin{array}{c}\text { Line } \\
8-9\end{array}$ \\
\hline 5 & $4-5$ & --- & 1.222 & 1.015 & 1.141 & 0.995 & 1.030 \\
\hline 5 & $5-7$ & 0.978 & --- & 1.064 & 1.117 & 0.993 & 1.057 \\
\hline 6 & $4-6$ & 0.982 & 0.920 & --- & 1.447 & 1.004 & 1.013 \\
\hline 6 & $6-9$ & 1.000 & 0.968 & 0.901 & --- & 1.019 & 0.927 \\
\hline 8 & $7-8$ & 1.027 & 1.034 & 0.966 & 1.000 & --- & 0.946 \\
\hline 8 & $8-9$ & 1.139 & 1.083 & 0.993 & 0.979 & 0.951 & --- \\
\hline
\end{tabular}

Here, trajectory sensitivity method is used to find the location, which improves the stability margin to maximum. Figures 4 depicts the relative rotor angle oscillations of $\delta_{21}$ (i.e., delta21) are $83.13^{\circ}$ and $\delta_{31}$ (i.e., delta31) are $56.12^{\circ}$ during fault condition without any compensation. 
Figure 5 shows the plot of relative angle Vs time for the fault at $7^{\text {th }}$ bus, line 5-7 is opened, and the clearing time of $0.0873 \mathrm{Sec}$ with $50 \%$ compensation. From this figure, it can be observed that relative rotor angle oscillations of $\delta_{21}$ (i.e., delta21) reduced to $67.16^{\circ}$ and $\delta_{31}$ (i.e., delta31) reduced to $34.81^{\circ}$ during fault condition with fixed compensation. Figure 6 depicts the plot of relative angle Vs time for the fault at $7^{\text {th }}$ bus, line 5-7 is opened, the clearing time of $0.0873 \mathrm{Sec}$ with $\mathrm{K}_{\mathrm{P}}=0.8, \mathrm{~K}_{\mathrm{I}}=9$, and the TCSC is located in line 6-9. From this Figure 6, it is clear that relative rotor angle oscillations of $\delta_{21}$ (i.e., delta21) is $47.7^{\circ}$ and $\delta_{31}$ (i.e., delta31) is $24.3^{\circ}$ and these values are reduced to a great extent during fault condition with TCSC. This shows the improvement in transient stability margin using TCSC.

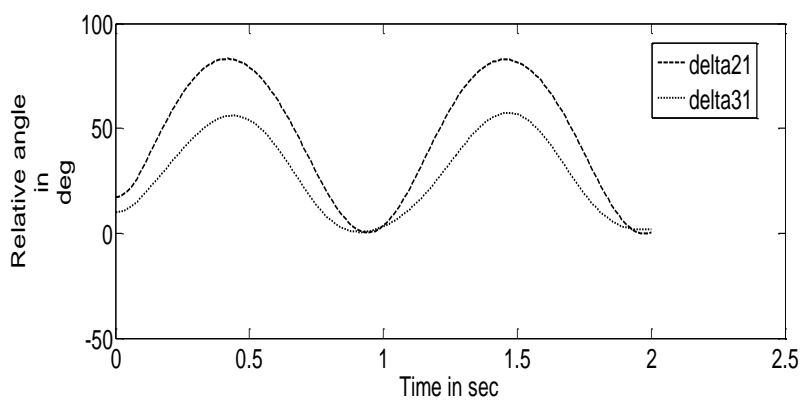

Figure 4. Relative angle vs time plot for the fault at $7^{\text {th }}$ bus, line 5-7 is opened.

Clearing time $0.0873 \mathrm{Sec}$.

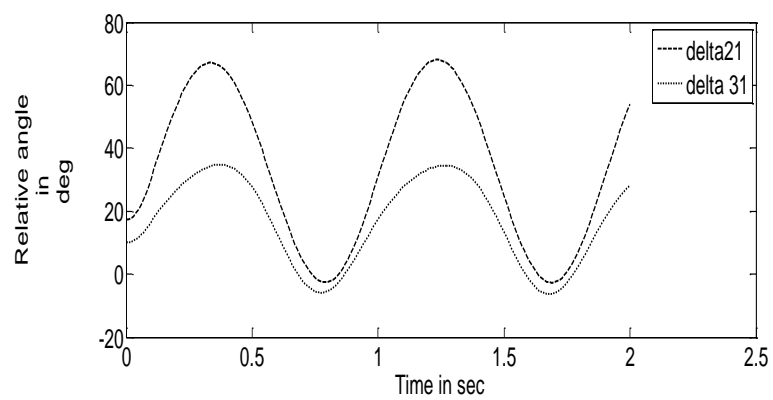

Figure 5. Relative angle vs time plot for the fault at $7^{\text {th }}$ bus, line 5-7 is opened.

Clearing time is $0.0873 \mathrm{Sec}$ with $50 \%$ compensation.

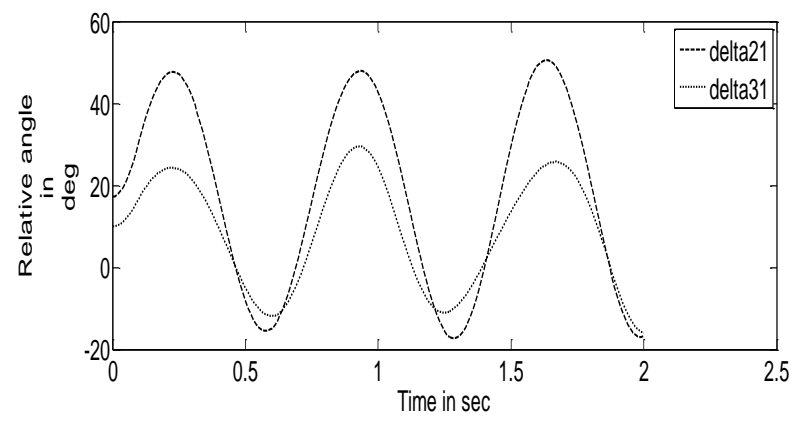

Figure 6. Relative angle vs time plot for the fault at $7^{\text {th }}$ bus, line 5-7 is opened. Clearing time is $0.0873 \mathrm{Sec}$ with $\mathrm{K}_{\mathrm{P}}=0.8, \mathrm{~K}_{\mathrm{I}}=9$. TCSC is located in line 6-9. 
Mostly the system stability conditions are improved by using TCSC, when it is located in line 5-7 or 6-9 line. Therefore, effect of TCSC with controller in these two locations is studied in this case. Another interesting issue is the comparison between TCSC without a controller (i.e., open loop) and the effects of TCSC controller. In open loop, TCSC works as a fixed capacitor throughout the period of disturbance, and it is termed as fixed capacitor mode of operation. Here, the effects of a TCSC controller and fixed capacitor combination on TS condition are examined and compared. For the system without TCSC, the fault duration is increased up to the critical clearing time (tcr). For a line isolated fault at bus 7, the obtained tcr is $0.18 \mathrm{sec}$. Figure 7 depicts the relative angle vs time plot for the fault at $7^{\text {th }}$ bus, line 5-7 is opened with clearing time of $0.18 \mathrm{Sec}$.

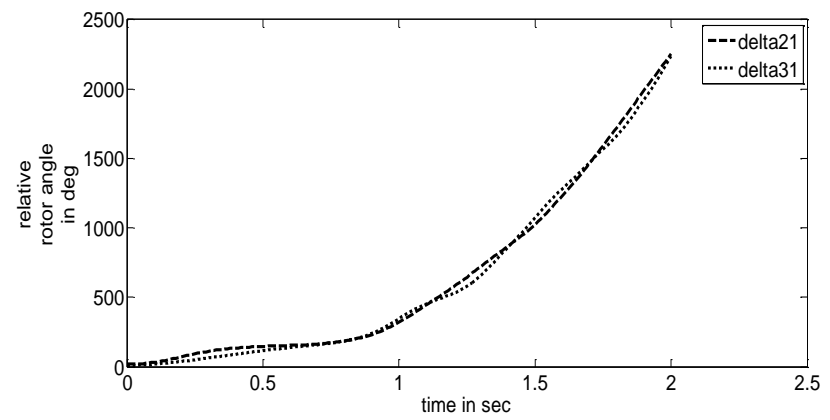

Figure 7. Relative angle vs time plot for the fault at $7^{\text {th }}$ bus, line 5-7 is opened with clearing time of $0.18 \mathrm{Sec}$.

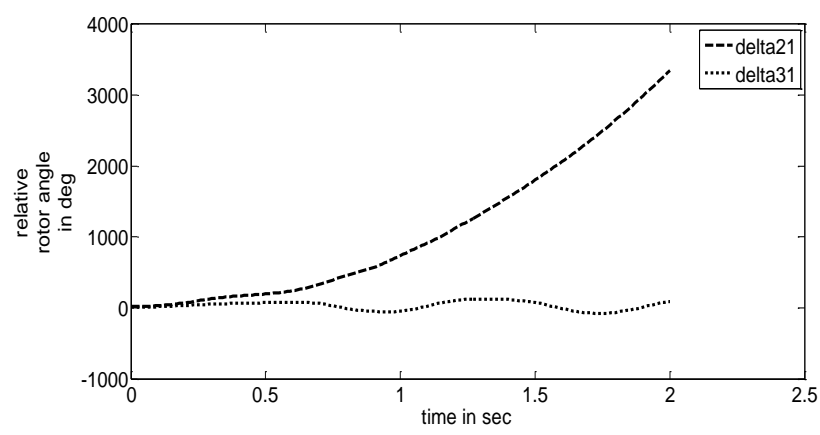

Figure 8. Relative angle vs time plot for the fault at $7^{\text {th }}$ bus, line 5-7 is opened, and the clearing time of $0.22 \mathrm{Sec}$ with $50 \%$ fixed compensation.

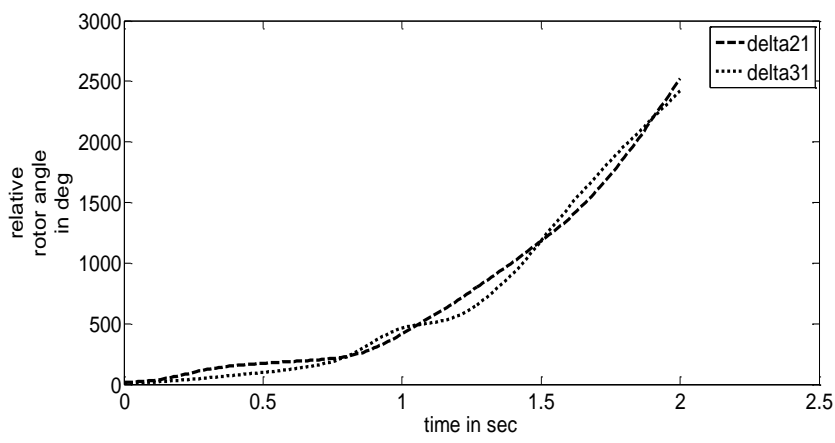

Figure 9. Relative angle vs time plot for the fault at $7^{\text {th }}$ bus, line 5-7 is opened, clearing time of $0.245 \mathrm{Sec}$ with $\mathrm{K}_{\mathrm{P}}=0.8, \mathrm{~K}_{\mathrm{I}}=9$ and TCSC placed in line 6-9. 
The system gets unstable for a tcl more than the tcr. But, by placing the TCSC at suitable location and by choosing the optimum controller constants values, the system continues to remain stable even for a higher tcl. The fault duration is taken as $0.245 \mathrm{sec}(>\mathrm{tcr})$ and the relative rotor angle $\delta_{21}$ for two cases, i.e., system without and with TCSC at line 6-9 are plotted.

The obtained relative rotor angle is found to diverge and become unbounded in case of system without TCSC, but it remains bounded and stable by placing the TCSC in line 6-9. Figure 8 depicts the relative angle vs time plot for the fault at $7^{\text {th }}$ bus, line 5-7 is opened, and the clearing time of $0.22 \mathrm{Sec}$ with $50 \%$ fixed compensation. Figure 9 shows the plot for fault at $7^{\text {th }}$ bus, line 5-7 is opened, clearing time of $0.245 \mathrm{Sec}$ with $\mathrm{K}_{\mathrm{P}}=0.8, \mathrm{~K}_{\mathrm{I}}=9$ and TCSC placed in line 6-9.

\section{B. Simulation Results on 5 Bus System}

Table 2 presents the normalized values of $\eta$ for various combinations of TCSC, and the fault locations when faults cleared by line isolation. Faults are assumed to be located near one of the load demand buses $(2,3,4$ or 5$)$ in all the case studies. The value of fault clearing time (tc1) is considered as $0.1 \mathrm{~s}$ and $\alpha$ of TCSC as $130^{\circ}$.

Table 2. Normalized $\eta$ (ETA) values of 3 bus system for TCSC placed in different fault locations.

\begin{tabular}{|c|c|c|c|c|c|c|c|c|}
\hline $\begin{array}{c}\text { Fault at } \\
\text { the bus }\end{array}$ & $\begin{array}{c}\text { Line } \\
\text { Isolated }\end{array}$ & $\begin{array}{c}\text { Line } \\
1-2\end{array}$ & $\begin{array}{c}\text { Line } \\
1-3\end{array}$ & $\begin{array}{c}\text { Line } \\
2-3\end{array}$ & $\begin{array}{c}\text { Line } \\
2-4\end{array}$ & $\begin{array}{c}\text { Line } \\
2-5\end{array}$ & $\begin{array}{c}\text { Line } \\
3-4\end{array}$ & $\begin{array}{c}\text { Line } \\
4-5\end{array}$ \\
\hline 2 & $2-1$ & --- & 1.1897 & 1.0193 & 1.0129 & 0.9936 & 1.0064 & 1.0129 \\
\hline 2 & $2-3$ & 1.0465 & 1.0155 & --- & 0.9978 & 1.0000 & 0.9978 & 1.0000 \\
\hline 2 & $2-4$ & 1.0465 & 1.0176 & 0.9978 & --- & 1.0000 & 0.9978 & 1.0000 \\
\hline 2 & $2-5$ & 4.4530 & 4.3425 & 4.2592 & 4.2592 & --- & 4.2592 & 4.2592 \\
\hline 3 & $3-1$ & 1.0975 & --- & 1.0182 & 1.0130 & 1.0039 & 0.9908 & 0.9960 \\
\hline 3 & $3-2$ & 1.0690 & 1.0351 & --- & 1.0075 & 1.0012 & 0.9924 & 0.9962 \\
\hline 3 & $3-4$ & 1.0681 & 1.0260 & 1.0144 & 1.0086 & 1.0000 & --- & 0.9956 \\
\hline 4 & $4-2$ & 1.0694 & 1.0322 & 1.0062 & --- & 1.0024 & 0.9937 & 0.9975 \\
\hline 4 & $4-5$ & 1.0716 & 1.0327 & 1.0113 & 1.0213 & 1.0050 & 0.9937 & --- \\
\hline 5 & $5-2$ & 1.0670 & 1.0270 & 0.9939 & 0.9939 & --- & 1.0020 & 0.9849 \\
\hline
\end{tabular}

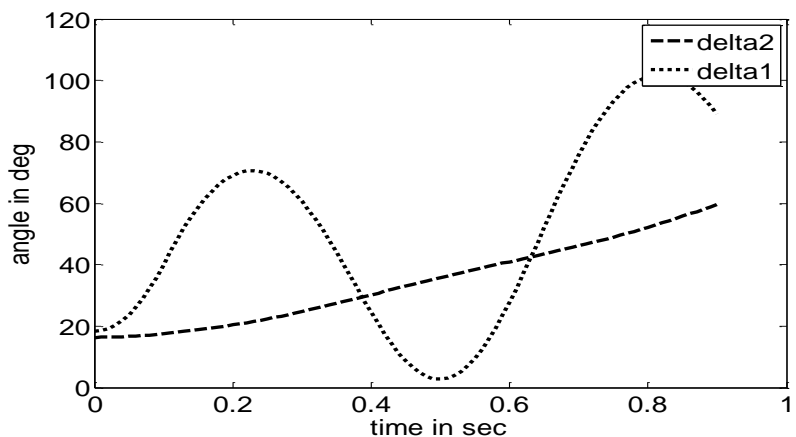

Figure 10. Relative angle vs time plot for the fault at $2^{\text {nd }}$ bus, line $2-5$ is opened, clearing time of $0.1 \mathrm{sec}$.

Figure 10 depicts the relative rotor angle oscillations of $\delta_{21}$ (i.e., delta21) is $49.36^{\circ}$ during fault condition without any compensation. From figure 11, it can be observed that the relative rotor angle oscillations of $\delta_{21}$ (i.e., delta21) reduced to $45.52^{\circ}$ during fault condition with fixed compensation. From figure 12, it can be seen that the relative rotor angle oscillations of $\delta_{21}$ $\left(42.3^{\circ}\right)$ reduced to a great extent during fault condition with TCSC. This shows the improvement of transient stability margin using TCSC. 


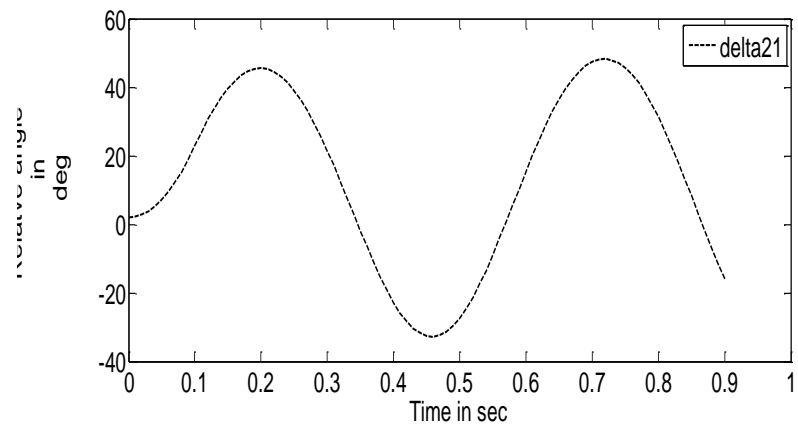

Figure 11. Relative angle vs time plot for the fault at $2^{\text {nd }}$ bus, line 2-5 is opened, clearing time of $0.1 \mathrm{sec}$ with $50 \%$ fixed compensation.

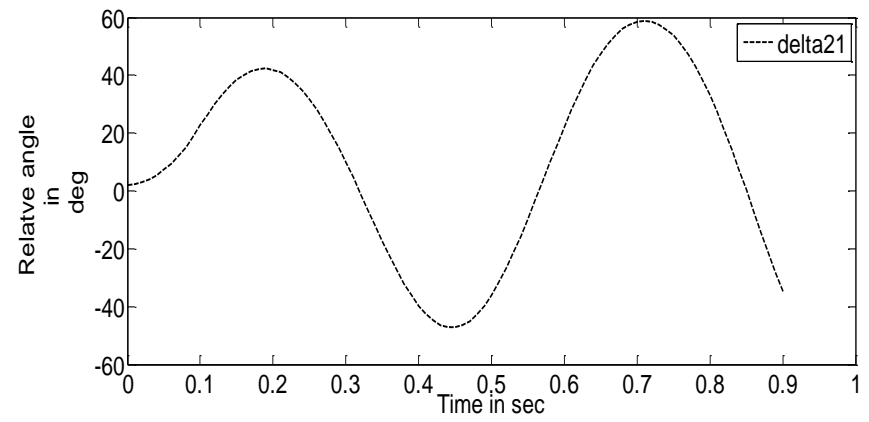

Figure 12. Relative angle vs time plot for the fault at $2^{\text {nd }}$ bus, line 2-5 is opened, clearing time of $0.1 \mathrm{sec}$ with $\mathrm{K}_{\mathrm{P}}=0.8, \mathrm{~K}_{\mathrm{I}}=9$ and TCSC placed in line 1-2.

The fault duration is increased up to tcr for the system without TCSC. For a line isolated fault at bus 2, the obtained value of tcr is $0.19 \mathrm{sec}$ (Figure 13). Therefore, the system gets unstable for a tcl more than this tcr. But, by placing the TCSC at suitable location and by properly choosing the controller constants values, the system continues to remain stable even for a higher fault clearing time (Figure 14). The fault duration is considered as $0.22 \mathrm{sec}$ (>tcr) and the relative rotor angle $\delta_{21}$ for two cases, i.e., system without TCSC and with TCSC in line 2-5 are depicted in Figures 14 and 15, respectively.

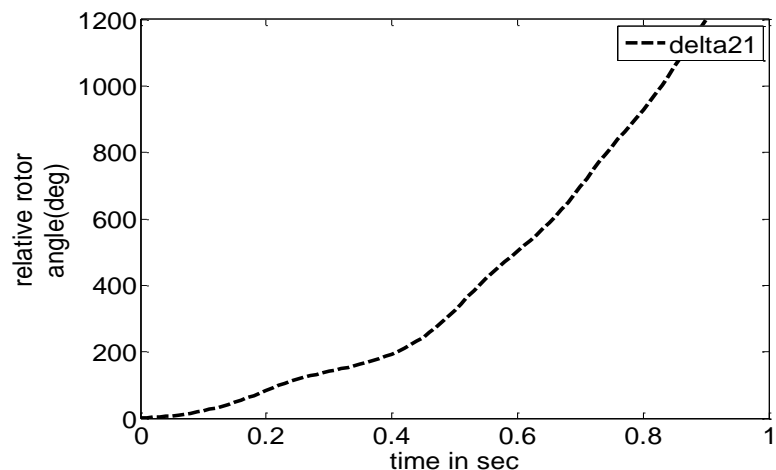

Figure 13. Relative angle vs time plot for the fault at $2^{\text {nd }}$ bus, line 2-5 is opened, clearing time of $0.19 \mathrm{sec}$. 


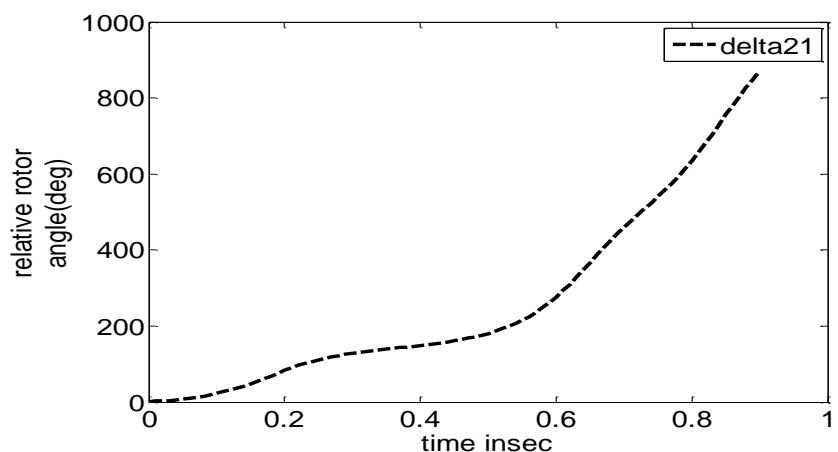

Figure 14. Relative angle vs time plot for the fault at $2^{\text {nd }}$ bus, line 2-5 is opened, clearing time of $0.2 \mathrm{sec}$ with $50 \%$ fixed compensation.

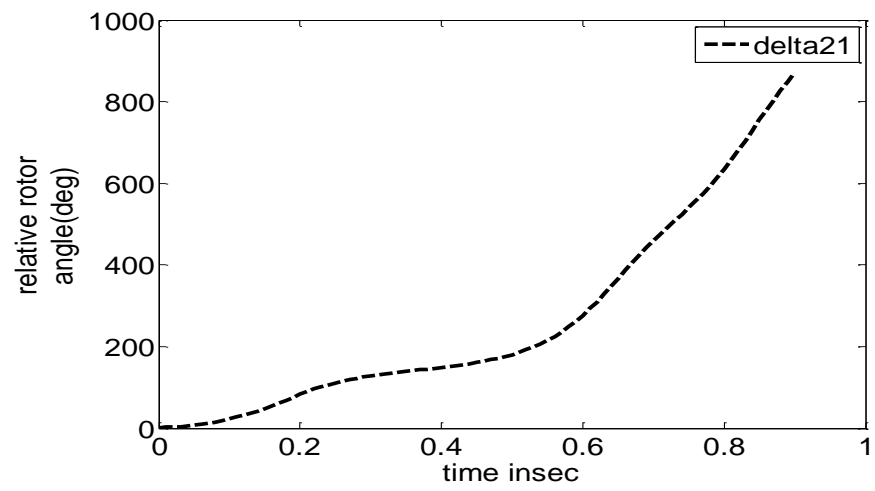

Figure 15. Relative angle vs time plot for the fault at $2^{\text {nd }}$ bus, line 2-5 opened, critical clearing time of $0.22 \mathrm{sec}$ with $\mathrm{K}_{\mathrm{P}}=0.8, \mathrm{~K}_{\mathrm{I}}=9$ and TCSC placed in line 1-2.

The above simulation results depicts the effectiveness and suitably of TCSC with appropriately designed controller to enhance the TS of power system. Here, a Proportional Integral controller is used for the effective use of TCSC in the multi-machine power network to enhance the TS margin.

\section{Conclusions}

This paper addresses the enhancements of transient stability (TS) using TCSC. The detailed analysis of TS needs complete modeling of generators, and other related equipments. The time domain simulation is the most practical available technique for transient stability analysis. In this paper, network reduction techniques or step by step approach are used to solve the non-linear differential equations. Here, the TS analysis of Western System Coordinating Council (WSCC) 9 bus test system is used to perform different cases such as faults of self clearing type, fault cleared by line removal, etc. The damping of system is included, and the analysis shows better results. The case studies presents the optimal placement of fixed compensation in the system as line 6-9, and it is based on the first swing peak value. TCSC controller has been modeled and assigned at optimal placement. The simulation results present the effectiveness and suitability of application of TCSC in enhancing the TS of power system.

\section{Acknowledgments}

This research work is based on the support of "Woosong University's Academic Research Funding - 2018”. 


\section{References}

[1]. Y. Mehmet, S. Ermis and R. Bayindir, "Investigation of the effects of FACTS devices on the voltage stability of power systems", $\sigma^{\text {th }}$ IEEE International Conference on Renewable Energy Research and Applications (ICRERA), 2017, pp. 1080-1085.

[2]. P. Kundur, J.Paserba, "Definition and Classification of Power System Stability", IEEE Trans. Power Syst., vol. 19, no. 2, pp 1387-1401, May 2004.

[3]. Z. Čonka, M. Kolcun, "Impact of TCSC on the Transient Stability", Acta Electrotechnica et Informatica, vol. 13, no. 2, pp. 50-53, 2013.

[4]. K.R.Padiyar, "HVDC Power Transmission Systems", New Age International Ltd., 2004.

[5]. T.L. Duong, Y.J. Gang, V.A. Truong, "Improving the transient stability-constrained optimal power flow with Thyristor Controlled Series Compensators", Russian Electrical Engineering, vol. 85, no. 12, pp. 777-784, Dec. 2014.

[6]. D. Chatterjee, A. Ghosh, "TCSC control design for transient stability improvement of a multi-Machine power system using trajectory sensitivity", Electric Power Systems Research, vol. 77, pp. 470-483, 2007.

[7]. R. Suguna, S. Jalaja, M. Pradeep, R.S. Kumar, S.S. Kumar, K.R. Sugavanam, “Transient Stability Improvement using Shunt and Series Compensators", Indian Journal of Science and Technology, vol. 9, no. 11, pp. 1-11, Mar. 2016.

[8]. P. Sunil kumar, "Transient Stability Enhancement of Power System Using TCSC", Int. Journal of Electrical and Computer Engineering, vol.2, no.3, pp. 317-324, Jun. 2012.

[9]. D. Rosso, C.A. Canizares, V.M. Dona, "A study of TCSC controller design for power system Stability improvement”, IEEE Trans. Power Syst., vol.18, no.4, pp.1487-1496, Nov. 2003.

[10]. R. Shankar, J. Srivastava, “Transient Stability Study by Using Thyristor Controlled Series Compensator Controller for Single Machine Infinite Bus (SMIB) System", International Journal of Engineering Science and Innovative Technology, vol. 2, no. 5, Sept. 2013.

[11]. P. Kumkratug, "The Effect of Thyristor Controlled Series Capacitor on Transient Stability of Single Machine Infinite Bus System with the Exact Short Transmission Line Model", American Journal of Applied Sciences, vol. 9, no. 3, pp. 425-428, 2012.

[12]. G. Srinivasa Rao, A. Srujana, "Transient Stability Improvement of Multi-machine Power System Using Fuzzy Controlled TCSC", Int. Journal of Advancements in Research \& Technology, vol. 1, no. 2, Jul. 2012.

[13]. S. Khan, S. Bhowmick, "A Fuzzy TCSC Controller for transient stability improvement", 2015 Annual IEEE India Conference (INDICON), New Delhi, 2015, pp. 1-5.

[14]. H.T. Hassan, U.F. Malik, I.A. Khan, T. Khalid, "Stability Improvement of Power System Using Thyristor Controlled Series Capacitor (TCSC)", International Journal of Engineering \& Computer Science, vol. 13, no. 2, pp. 30-34, 2013.

[15]. A. Zahra, S. Ghazanfar, "Power System Transient Stability Enhancement with TCSC Controller Using Genetic Algorithm Optimization", International Journal of Natural \& Engineering Sciences, vol. 10, no. 3, pp. 9-15, 2016.

[16]. A. Halder, N. Pal, D. Mondal, "Transient Stability Analysis of a Multi-machine Power System with TCSC Controller - A Zero Dynamic Design Approach", International Journal of Electrical Power \& Energy Systems, vol. 97, pp. 51-71, Apr. 2018.

[17]. M. Bakhshi, M.H. Holakooie, A. Rabiee, "Fuzzy based damping controller for TCSC using local measurements to enhance transient stability of power systems", International Journal of Electrical Power \& Energy Systems, vol. 85, pp. 12-21, Feb. 2017.

[18]. S.K. Rautray, S. Choudhury, S. Mishra, P.K. Rout, "A Particle Swarm Optimization based Approach for Power System Transient Stability Enhancement with TCSC", Procedia Technology, vol. 6, pp. 31-38, 2012.

[19]. N.N. Islam, M.A. Hannan, A. Mohamed, H. Shareef, "Improved Power System Stability Using Backtracking Search Algorithm for Coordination Design of PSS and TCSC Damping Controller”, PLoS One, vol. 11, no. 1, pp. 1-17, Jan. 2016. 
[20]. S. Hasanvand, H.F. Abarghouei, "Power System Stability Improvement in Presence of Renewable Energies and TCSC", IETE Journal of Research, vol. 61, no. 6, pp. 686-692, 2015.

[21]. M.A.H. Sadi, M.H. Ali, "Transient stability enhancement by bridge type fault current limiter considering coordination with optimal reclosing of circuit breakers ", Electric Power Systems Research, vol. 124, pp. 160-172, Jul. 2015.

[22]. P.R. Gandhi, S.K. Joshi, "Smart control techniques for design of TCSC and PSS for stability enhancement of dynamical power system", Applied Soft Computing, vol. 24, pp. 654-668, Nov. 2014.

[23]. D.A. Ingole, V.N. Gohokar, "Voltage Stability Improvement In Multi-bus System Using Static Synchronous Series Compensator", Energy Procedia, vol. 117, pp. 999-1006, Jun. 2017.

[24]. G. Shahgholian, A. Movahedi, J. Faiz, "Coordinated Design of TCSC and PSS Controllers using VURPSO and Genetic Algorithms for Multi-Machine Power System Stability", International Journal of Control, Automation and Systems, vol. 13, no. 2, pp. 398-409, Apr. 2015.

[25]. A. Rezazadeh, M. Sedighizadeh, A. Hasaninia, "Coordination of PSS and TCSC Controller using Modified Particle Swarm Optimization Algorithm to Improve Power System Dynamic Performance”, Journal of Zhejiang University SCIENCE C, vol. 11, no. 8, pp. 645-653, Aug. 2010.

[26]. A.D. Falehi, A. Mosallanejad, "Dynamic Stability Enhancement of Interconnected Multisource Using Hierarchical ANFIS Controller - TCSC Based on Multi-Objective PSO”, Frontiers of Information Technology \& Electronic Engineering, vol. 18, no. 3, pp. 394409, Mar. 2017.

[27]. M. Irfarfan, S. Kulkarni, P. Kulkarni, S. Wagh, N.M. Singh, "Transient Stability Improvement of Multi-Machine Power System using Higher Order Sliding Mode Control", IFAC Proceedings Volumes, vol. 47, no. 1, pp. 1054-1060, 2014.

[28]. M. Pert, T. Weckesser, M. Rezkalla, M. Marinelli, "Transient Stability Improvement: A Review and Comparison of Conventional and Renewable based Techniques for Preventive and Emergency Control", Electrical Engineering, vol. 100, no. 3, pp. 1701-1718, Sept. 2018 .

Nomenclature

$\mathrm{E}_{\mathrm{k}}^{\prime} \quad$ Voltage behind transient reactance.

$\mathrm{H} \quad$ Inertia constant.

n Number of generators in the system.

$\mathrm{E}_{\mathrm{T}} \quad$ Machine terminal voltage.

$\mathrm{E}_{\mathrm{p}} \quad$ Calculated bus voltage.

$\mathrm{P}_{\mathrm{lp}}, \mathrm{Q}_{\mathrm{lp}} \quad$ Scheduled real and reactive loads.

$\mathrm{r}_{\mathrm{a}} \quad$ Armature resistance.

$\mathrm{P}_{\mathrm{a}} \quad$ Accelerating power.

$\mathrm{P}_{\text {ref }} \quad$ Reference value of active power flow.

$\alpha \quad$ Delay/firing angle.

$\mathrm{I}_{\mathrm{t}} \quad$ Machine terminal current.

$\mathrm{x} \quad$ State vector.

$\lambda \quad$ Vector of system parameters.

$x_{d}^{\prime} \quad$ Transient reactance.

$\mathrm{X}_{\mathrm{C}} \quad$ Capacitor impedance/capacitive reactance.

$\mathrm{X}_{\mathrm{L}} \quad$ Reactor impedance/inductive reactance.

TCSC Thyristor controlled series compensator.

$\mathrm{C}_{\mathrm{TCSC}} \quad$ Capacitance of TCSC.

tcl Fault clearing time.

TS Transient stability. 
TSM Transient stability margin.

tcr Critical clearing time.

$\mathrm{T}_{\mathrm{cr}} \quad$ Critical clearing time.

$\mathrm{X}_{\mathrm{FC}} \quad$ Capacitive reactance.

$\mathrm{X}_{\mathrm{P}} \quad$ TCR reactance.

$\left|\mathrm{E}_{\mathrm{k}}\right| \quad$ Generator emf magnitude.

$\delta_{\mathrm{k}}^{0} \quad$ Initial rotor angle.

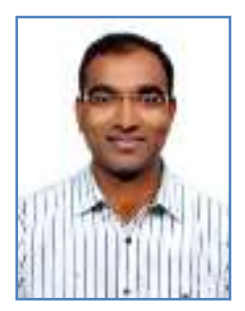

Surender Reddy Salkuti received the Ph.D. degree in electrical engineering from the Indian Institute of Technology Delhi, New Delhi, India, in 2013. He was a Post-Doctoral Researcher at Howard University, Washington, DC, USA, from 2013 to 2014. He is currently working as an Assistant Professor with the Department of Railroad and Electrical Engineering, Woosong University, Daejeon, Republic of Korea. His current research interests include power system restructuring issues, ancillary service pricing, active and reactive power pricing, congestion management, and market clearing, including renewable energy sources, demand response, smart grid development with integration of wind and solar photovoltaic energy sources, artificial intelligence applications in power systems, and power system analysis and optimization. 